\title{
Simulation of land use changes for the planning of a metropolitan area
}

\author{
S. Kanchanamala \& S. P. Sekar \\ Department of Planning, Anna University, India
}

\begin{abstract}
An urban system is complex and so it can respond in more than one way to its environment. Urban land use dynamics are the direct consequence of the action of individuals, public and private agents acting simultaneously in time over the urban space. Urban land use represents an intense and complete transformation of the natural environment for its essential construction of urban fabrics including residential, industrial and infrastructure development which is driven by population growth, social and economic development. Urban planning usually involves the comparison between a set of planning scenarios and development options before making a plan. The analysis of alternative planning options is an essential part of plan making. Every time an urban land use plan is prepared, the urban planners are under pressure with limited resource availability and time frame. The plans are therefore prepared without application of an appropriate scientific tool or urban model, to minimise resource and time and so the plans suffer validation. Further, evaluation of the plans in the mid-course with the ground reality and modification wherever necessary is possible only when they have suitable tools in hand to prepare alternate plans. Such a plan will encounter fewer errors and be more successful.

In this context, the paper attempts to develop a tool for the planners to help them in assessing the future development in a metropolitan context at any given point of time. The variables which influence urban land use change are identified and a land use simulation model is developed to simulate future land use scenarios. The land use scenarios guide in forecasting the future requirements of infrastructure and communal facilities. The model is demonstrated with a village level case study in Chennai Metropolitan Area.

Keywords: urban planning, land use change, variables influencing land use change, simulation model, scenario planning.
\end{abstract}




\section{Introduction}

Urban land use dynamics are the direct consequence of the action of individuals, public and private corporations acting simultaneously in time over the urban space. As a consequence, cities are the spatial result in time of all these influences, which continuously contribute to shape the city (Barredo et al. [1]). Urban land use represents an intense and complete transformation of the natural environment for its essential construction of urban fabrics including residential, industrial and infrastructure development. Urban land use expansion is driven by population growth, social and economic development (Liu and Prieler [2]).

Land use change in metropolitan areas typically reflects economic development and population growth. Thus the analysis of spatial-temporal patterns for land use/cover provides an objective basis for understanding the relationships between urban growth and related economic, population and environmental factors. Change detection for land use/cover categories, through the integration of satellite imagery, environmental and socio-economic data, has been commonly used for the analysis of the dynamic pattern of urban growth (Liu and Zhou [3]). Land use planning is the most essential process in the management of urban areas. White et al. [4] points out that effective planning and management requires both data on current conditions and an ability to foresee the likely consequences of proposed projects and policies. Efficient modelling of urban system has become a pre-requisite for effective management and functioning of the urban areas. The present set up in the planning of Indian cities urges the need for the availability of simple, flexible, resource and time efficient urban models for successful planning and management of urban areas. Such a tool capable of supporting the generation of urban land use scenarios will be beneficial for the urban planners to generate alternate plans for decision making. Recently, cellular automata (CA) have gained popularity as modelling tools for urban process simulation.

The aim of this paper is to develop cellular automata based land use simulation model in the context of metropolitan sub urban area. The first part of the paper discusses the dynamics in urban land use change, the variables which influence urban growth, the components and design of the model. The second part deals with the application of the model for the sub urban case study area of Thirumazhisai in Chennai Metropolitan Area, and the results of the simulation model.

\section{Modelling land use change dynamics}

Bhatta [5] emphasises how 'land cover' differs from 'land-use'. 'Land-cover' corresponds to the physical condition of the ground surface, for example, forest, grassland, cropland, and water; while 'land-use' reflects human activities such as the use of the land, for example, industrial, residential, recreational, and agricultural. Land-cover refers to features of land surface, which may be natural, semi-natural, managed, or manmade. They are directly observable by a remote sensor, whereas, land-use refers to activities on land, or classification of land 
according to how it is being used. Basically, urban planning organisations consider land use than land cover in the analysis of urban growth for making land use plans. The urban growth process is a self-organized system Cheng and Masser [6]. The term 'process' generally refers to a sequence of changes in space and time-spatial processes and temporal processes, respectively.

\subsection{Variables influencing urban growth}

Several studies had identified different sets of variables which influence urban growth. Yeh and Li [7] had identified seven spatial variables to represent the site attributes of each cell for the simulation of urban development viz., (i) distance to the major urban areas; (ii) distance to suburban areas; (iii) distance to the nearest road; (iv) distance to the nearest expressway; (v) distance to the nearest railways; (vi) neighbourhood development level; and (vii) agricultural suitability. Maithani [8] had identified that urban growth is defined as a function of the following three factors, also called as causative factors which are (i) accessibility to roads (connectivity is a major factor affecting the urban growth process); (ii) accessibility to the city core, (most of the higher level facilities are located in the city core); and (iii) accessibility to infrastructural facilities. Almeida et al. [9] had used an extensive list of twelve variables for determining urban land use change through simulation viz., (i) area served by water supply; (ii) mediumhigh density of occupation ( $25 \%$ to $40 \%$ ); (iii) existence of social housing, (iv) distances to ranges of commercial concentration; (v) distances to industrial zones; (vi) distances to residential zones; (vii) distances to peripheral residential settlements; (viii) distances to isolated institutional use; (ix) distances to main existent roads; (x) distances to the service and industrial axes; (xi) distances to planned roads; and (xii) distances to peripheral roads.

This research uses four variables in the simulation model for land use change analysis. They are (i) accessibility to transportation networks; (ii) physical quality and land availability; (iii) proximity to work places; and (iv) plans and policies.

\section{Model structure}

$\mathrm{Li}$ and Yeh [10] explain that simulation of urban growth is normally done on a binary basis, i.e., land is either assigned or not assigned for urban development. Cellular automata based urban growth models are the most sought after models for their simplicity. Torrens [11] suggests that cellular automata can be useful in simulating urban systems because land use, concentrations of employment location and population change can all be modelled as automata; cells can effectively aggregate economic, demographic and transportation data; neighbourhoods as part of the city scape can be successfully simulated by equivalent neighbourhoods of cells on the cellular lattice; and even urban theories based on spatial interaction models can be tested and represented. The approach is particularly useful for representing the interactions between a location and its immediate environment, but tends to reflect a fairly abstract 
representation of agents, decisions, and behaviour, since the models focus on simulating the change in state of individual cells (Waddell and Ulfarsson [12]).

CA are models in which contiguous or adjacent cells, such as those of that might comprise a rectangular grid, change their states - their attributes or characteristics- through the repetitive application of simple rules (Batty [13]). The rules for transition from one cell state to another can be interpreted as the generators of growth or vice versa. This change is a function of what is going on in the neighbourhood of the cell, the neighbourhood usually being defined as immediately adjacent cells, or cells that "in some sense" are nearby. The principle can be stated in its most generalized form as

"IF something happens in the neighbourhood of a cell

THEN some-other-thing happens to the cell".

The above rule will result in a pattern containing randomly located vacant sites. Therefore the rule is modified so as to generate an entirely compact urban form in the following way:

"IF there is at least one developed cell in the Moore neighbourhood around the cell in question

THEN the cell is developed with a probability $\rho$ ".

CA models can be implemented within many types of software. It is possible to program them in spreadsheets such as Excel using the chart function as a means of displaying the 2-dimensional grid, and this is aided even further if the modules for plotting maps within the spreadsheet are available. CA models can be easily developed that use the extensive graphics capabilities of GIS and computer aided design systems packages.

\subsection{Components of $\mathrm{CA}$}

A conventional cellular automaton consists of five components [1] viz., (i) a Euclidean space divided into an array of identical cells; (ii) a cell neighbourhood; (iii) a set of discrete cell states; (iv) a set of transition rules, which determine the state of a cell as a function of the states of cells in the neighbourhood; and (v) discrete time steps, with all cell states updated simultaneously.

Adopting a strict CA model is possible in the research laboratories. The planning organisations, however, with paucity for resources, accurate historic data and very limited time frame need a simplified tool which does not require expertise for application in real time cases. Therefore the basic principle of CA in formulating the components for simulation is adopted in this research using the software tools - PHP SQL dataset and JSP.

\subsection{Specifications of the model}

The specifications of the CA based land use simulation model are given in Table 1.

As seen from Table 1, the model adopts a two dimensional grid with a cell size of $150 \mathrm{~m} \times 150 \mathrm{~m}$ and 9 cells Moore neighbourhood, i.e., the cell under consideration in the centre surrounded by 8 other cells. The permanent features, mostly under the control of the respective Government agencies cannot be 
Table 1: Specifications of the proposed CA based simulation model.

\begin{tabular}{|c|c|}
\hline Item & Specification \\
\hline Lattice & $\begin{array}{l}\text { Two dimensional grid covering the case study area. The } \\
\text { case study area is treated as a closed system. }\end{array}$ \\
\hline Shape of cell & Square \\
\hline Size of cell & $150 \mathrm{~m} \times 150 \mathrm{~m}$ \\
\hline Shape and size of neighbourhood & $3 \times 3$ cells square grid - Moore neighbourhood \\
\hline Number of cell states & 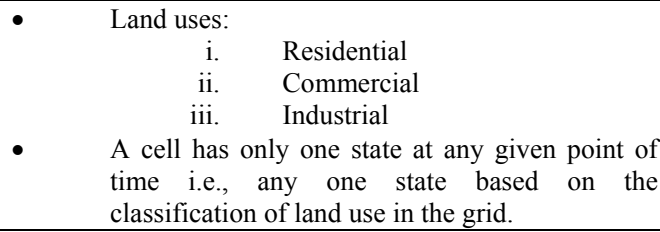 \\
\hline Transition rule & $\begin{array}{l}\text { Each cell attains the cell state (or the land use) which gets } \\
\text { maximum weightage among the three cell states } \\
\text { depending upon the parameter weightages for the cell in } \\
\text { relation to its neighbourhood. }\end{array}$ \\
\hline Permanent features & $\begin{array}{cl}\text { i. } & \text { Road and rail networks } \\
\text { ii. } & \text { Rivers/canals and water bodies } \\
\text { iii. } & \text { Pubic open spaces and facilities }\end{array}$ \\
\hline $\begin{array}{l}\text { Application of model depending } \\
\text { on scale of the area }\end{array}$ & $\begin{array}{l}\text { Can be applied to any scale with internal modifications in } \\
\text { the parameters and their weightages based on local } \\
\text { conditions. }\end{array}$ \\
\hline
\end{tabular}

altered and so they do not participate in the land use change dynamics, though they exert significant influence over the system. Also, the already developed areas are retained without allowing them to participate in the land use change dynamics. However, they also exert significant influence on the development of other cells forming part of the 9 cells Moore neighbourhood. Three cell states or land uses viz., residential, commercial and industrial uses are taken up for simulation. The model becomes considerably more complex when different activities are considered (Batty et al. [14]). Therefore, transition rules based on the weightages assigned to the parameters under each variable for the three cell states i.e., land uses are carefully drawn to evolve the probability of a cell for development. At the end of the simulation, the transition rule changes a cell to a cell state i.e., the land use with high land use suitability based on the scores of the weightages, than the other two cell states. The cell states are not changed if they have low land use suitability.

\section{Case study}

Thirumazhisai Town Panchayat is located at a distance of about $25 \mathrm{~km}$ from Chennai city along National Highway 4. The Town Panchayat (TP) consists of four villages namely, Thirumazhisai, Neduncheri, Madavilagam and Udayavarkoil. It extends over an area of 7.25 sq. km. The total population as per 2011 Census is 19733. The major activities are residential and industrial. 
The actual land use map for the year 1991 and 2006 from the Second Master Plan for Chennai Metropolitan Area are used in the simulations for the year 2006 and 2011. Figure 1 shows the actual land use during the year 1991 and 2006. Figure 2 shows the simulated land use for the year 2006 and 2011.

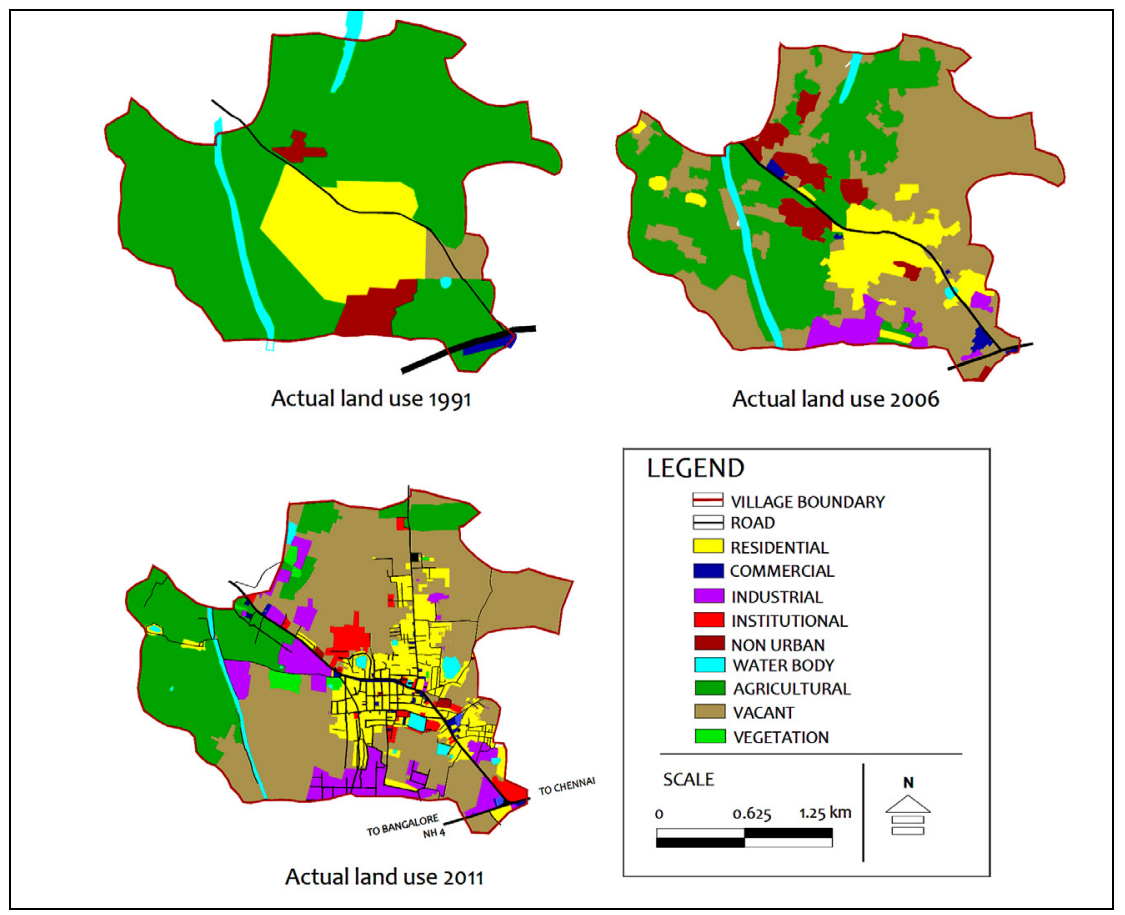

Figure 1: Actual land use in Thirumazhisai TP during the years 1991, 2006 and 2011. (Source: 1991 and 2006 maps from Second Master Plan for Chennai Metropolitan Area, 2026 (2008) and 2011 map from field survey.)

In order to calibrate the model, a comparison of the actual and simulated extents of different land uses in the year 2011 is given in Table 2. There is a correlation of over $60 \%$ in residential use and over $90 \%$ in industrial use. Also there is a good correlation in agricultural land use. However the simulation has not performed well with commercial use. 


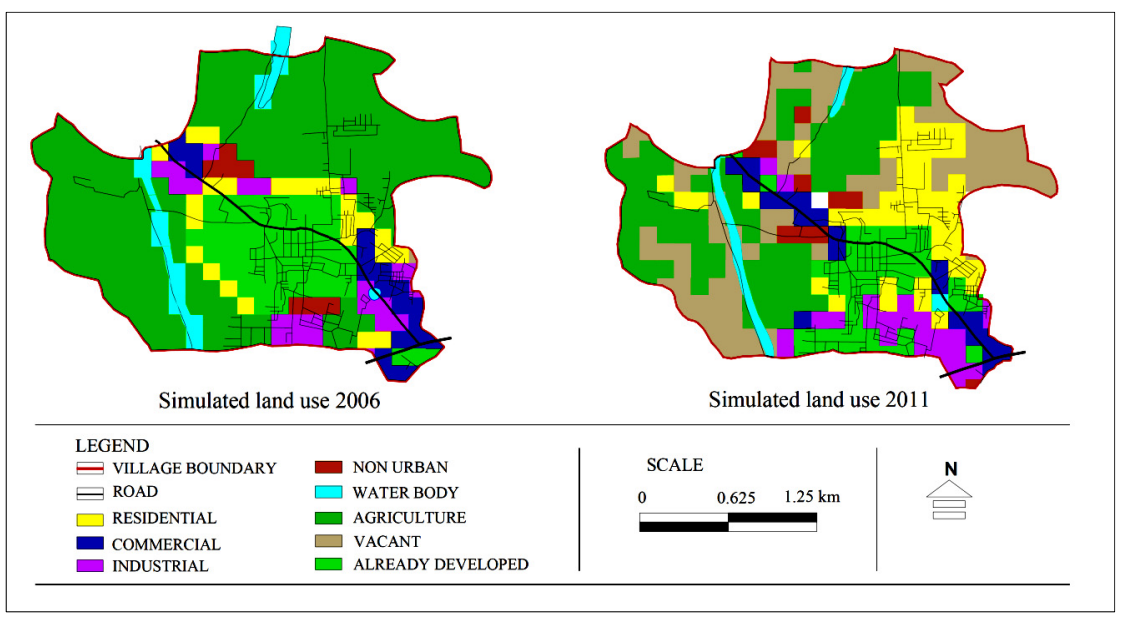

Figure 2: $\quad$ Simulated land use for the year 2006 and 2011.

Table 2: Comparison of actual and simulated extents during 2011.

\begin{tabular}{|l|c|c|c|}
\hline \multirow{2}{*}{ Land use } & Actual extent & Simulated extent & \multirow{2}{*}{$\begin{array}{c}\text { Percentage } \\
\text { correlation }\end{array}$} \\
\cline { 2 - 3 } & \multicolumn{2}{|c|}{ (in sq.km.) } & $61.40 \%$ \\
\hline Residential & 1.05 & 1.71 & $15.00 \%$ \\
\hline Commercial & 0.07 & 0.48 & $90.20 \%$ \\
\hline Industrial & 0.65 & 0.72 & $80.20 \%$ \\
\hline Agriculture & 1.60 & 2.00 & $53.33 \%$ \\
\hline Vacant & 3.45 & 1.84 & \\
\hline
\end{tabular}

\section{Results and discussion}

$\mathrm{Li}$ and Yeh [10] express that calibration of simulation model is extremely difficult when the conversion takes place among multiple land use types. Also, data limitations are a primary reason for the lack of fine-scale, spatially explicit analysis of urban systems. The actual land use maps for the year 1991 and 2006 show a contiguous development of residential use. However, the land use in 2011 shows a fragmented development. The comparison of actual and simulated land uses is therefore given only for the year 2011 to have a more realistic comparison. In spite of the draw back that the actual land use map for the year 2006 did not reflect the ground details accurately, the simulation model is capable of bringing out significant correlation. This is evident from the visual observation which shows the overlapping of the actual and simulated developed areas during 2006 and 2011. 
The calibration exercise has proven that the model is valid for application for simulation of land use changes subject to the availability of accurate historic data. The limitations in data accuracy shall be overcome if only the planning authorities update the data at regular intervals. By simulating the land use into the future and by incorporating the population, housing and infrastructure projections, different scenarios could be generated for assisting decision making. The case study area being a small Town Panchayat, the simulation was carried out without incorporating GIS. Building of CA functionality into GIS with remote sensing data will make the task much easier and quicker. For larger extents or for the simulation of land use changes for the metropolitan areas, the very same model could be coupled with GIS and remote sensing data.

\section{Conclusion}

A pragmatic rather than a theoretical approach is adopted in this research to make the process as simple as possible for adoption by urban planners in the planning process. The CA based simulation is flexible in the sense that the transition rules for any time period could be modified based on the inputs into the system and hence it is possible to generate scenarios from time to time for modifying the plans for successful implementation and evaluation.

\section{References}

[1] Barredo, Jose I., Kasanko, Marjo, McCormick, Niall \& Lavalle, Carlo., Modelling dynamic spatial processes: simulation of urban future scenarios through cellular automata. Landscape and Urban Planning, Volume 64, pp. 145-160, 2003.

[2] Liu, Shenghe \& Prieler, Sylvia., Spatial Patterns and Dynamic Mechanisms of Urban Land Use Growth in China: Case studies in Beijing and Shangai. Interim Report IR-02-005, International Institute for Applied Systems Analysis; Schlossplatz1, A-2361, Laxenburg, Austria, 2002.

[3] Liu, Huiping \& Zhou, Qiming., Developing urban growth predictions from spatial indicators based on multi-temporal images. Computers, Environment and Urban Systems, Volume 29, pp. 580-594, 2005.

[4] White, Roger., Engelen, Guy., Uljee, Inge., Lavalle, Carlo \& Erlich, Daniele., Developing an Urban Land Use Simulator for European Cities. Proc. of the 5th EC-GIS Workshop, Stresa, Italy, 1999.

[5] Bhatta, Basudeb., Urban growth and sprawl (Chapter 1). Analysis of urban growth and sprawl from remote sensing data, Springer-Verlag Berlin Heidelberg, pp. 1-16, 2010.

[6] Cheng, Jianquan \& Masser, Ian., Understanding spatial and temporal processes of urban growth: cellular automata modeling. Environment and Planning B: Planning and Design, Volume 31, pp. 167-194, 2004.

[7] Yeh, Anthony Gar-On \& Li, Xia., Urban simulation using Neural Networks and Cellular Automata for Land Use Planning (1). Symposium on Geospatial Theory, Processing and Applications, Ottawa, 2002. 
[8] Maithani, S., A Neural Network based Urban Growth Model of an Indian City. Journal of Indian Society for Remote Sensing, Volume 37, pp. 363376, 2009.

[9] Almeida, Claudia Maria De., Monteiro, Antonio Miguel Vieira., Camara, Gilberto., Soares-Filho, Britaldo Silveira., Cerqueira, Gustavo Coutinho., Araujo, William Leite and Pantuzzo, Alexandre Eduardo., Simulating urban land use change through CA-based modeling and logistic regression. Anais XI SBSR, Belo Horizonte, Brazil, pp. 1687-1694, 2003.

[10] Li, Xia \& Yeh, Anthony Gar-On., Neural-network-based cellular automata for simulating multiple land use change using GIS. International Journal of Geographical Information System, 16(4), pp. 323-343, 2002.

[11] Torrens, Paul M., Automata-based models of urban systems (Chapter 4). Advanced Spatial Analysis, ed. P. Longley \& M. Batty, ESRI Press, Redlands, pp. 61-79, 2003.

[12] Waddell, Paul and Ulfarsson, Gudmundur Freyr., Introduction to Urban Simulation: Design and Development of Operational Models. http://synthicity.com/introduction to urban simulation.pdf.

[13] Batty, Michael, Cellular Automata and Urban Form: A Primer. Journal of the American Planning Association, Spring 1997.

[14] Batty, M., Xie, Yichun and Sun, Zhanli., Modeling urban dynamics through GIS - based cellular automata. Computers, Environment and Urban Systems, Volume 23, pp. 205-233, 1999. 